\title{
Nova Versão Do Jogo Daphnia World: Aprendendo Ecotoxicologia De Forma Construtivista
}

\author{
Romulo Messias Silva Souza (1), Gisela de Aragão Umbuzeiro (2), \\ Marcos A. F. Borges(1). \\ (1) Laboratório de Informática, Aprendizagem e Gestão/ FT (LIAG) \\ (2) Laboratório de Ecotoxicologia e Microbiologia Ambiental Profo Dr. Abílio Lopes \\ (LEAL) \\ Faculdade de Tecnologia - Universidade Estadual de Campinas \\ Limeira - SP - Brasil. \\ romulomessias@me.com, giselau@ft.unicamp.br, \\ marcosborges@ft.unicamp.br
}

\begin{abstract}
Resumo. O resultado desse estudo foi a implementação de uma nova versão do jogo educacional Daphnia World, desenvolvido em HTML5 com programação Javascript. O objetivo do jogo Daphnia World é difundir o conhecimento sobre ecotoxicologia. Esse jogo utiliza de métodos construtivistas para conscientizar a população sobre a questão ambiental.
\end{abstract}

\begin{abstract}
The result of this article was of implement to a new version of a educational game called Daphnia World, developed in HTML5 with Javascript programming. The Daphnia World's objetives is to spread knowledge about ecotoxicology. This game uses constructivist methods to educate the people about environmental issues.
\end{abstract}

\section{Introdução}

Segundo a Pesquisa Nacional Amostra Domicilio, PNAD, de 2005 a 2011, o número de pessoas com mais de 10 anos com acesso a internet cresceu, aproximadamente, 144\% (IBGE, 2013). Junto a esse crescimento está o avanço da tecnologia Web, como ilustra a última versão do HTML (W3C, 2013), que permitiu um grande avanço na manipulação de conteúdo multimídia.

Devido a esse grande avanço tecnológico e a grande quantidade de pessoas com acesso à web, os jogos digitais se tornaram mais acessíveis. $O$ conjunto desses fatores torna os jogos digitais uma ferramenta poderosa para trazer a atenção do público para um determinado ponto (MORAIS, 2012), podendo ser qualquer assunto que se deseja dar atenção, como, por exemplo, ecotoxicologia.

Foi nesse contexto que o jogo "Daphnia World" foi criado, tendo como objetivo conscientizar a população a respeito da ecotoxicologia. A ecotoxicologia é um dos ramos da ecologia que estuda os efeitos de agentes tóxicos sobre diversos ecossistemas (TRUHAUT, 1977).

Objetivo deste projeto é melhorar a experiência do jogador oferecendo uma interface mais interessante e novos objetivos que possa explorar novos conceitos de ecotoxicologia , criando novas oportunidades de aprendizado. 
Este texto está organizado nas seguintes seções: a Seção 2 descreve os materiais e métodos utilizados para o desenvolvimento; a Seção 3 detalha a nova versão do jogo; a Seção 4 apresenta uma conclusão e a Seção 5 apresenta as referências bibliográficas citadas nesse texto.

\section{Materiais e Métodos}

O jogo foi desenvolvido usando o HTML como plataforma e o JavaScript como linguagem de programação. Para criar e alterar os elementos gráficos do projeto foi utilizado o software GIMP. A Seção 2.1 descreve a tecnologia HTML5 utilizada como plataforma base para o jogo. A Seção 2.2 descreve a linguagem de programação JavaScript, utilizada para lógica e manipulação e controle do jogo. A Seção 2.3 descreve o software GIMP, utilizado para edição de imagens para o jogo. A Seção 2.4 descreve a engine utilizada para facilitar o desenvolvimento.

\subsection{HTML}

O HTML 5 é a versão mais recente da linguagem de marcação de hipertexto para apresentar e estruturar o conteúdo na web. Com a nova versão do HTML, fica mais fácil manipular conteúdo multimídia sem a necessidade de instalação de plug-ins (W3C).

Para a manipulação de elementos gráficos, como animações, o HTML5 incorporou o elemento canvas. O canvas fornece uma série de métodos e propriedades que permitem definir um layout para apresentação e manipulação desses elementos gráficos (MOZZILA, 2013).

\subsection{JavaScript}

JavaScript é uma linguagem de programação orientada a objetos baseada em script, ou seja, não precisa de pré-processamento para ser executada. O navegador é o responsável por executá-la assim que a página é totalmente carregada.

Devido a essa característica, a aplicação se torna mais leve em termos de processamento para o servidor, visto que essa tarefa é responsabilidade do cliente (HAZAËL-MASSIEUX, 2013).

Neste projeto, o javasScript é utilizado para controlar o canvas, assim como toda a lógica do jogo.

\subsection{GIMP}

Para a criação e edição do elementos do jogo foi utilizado o software GIMP, software multiplataforma distribuído gratuitamente para a manipulação de gráficos vetoriais (GIMP). Nesse projeto foi utilizado a versão 2.8 do software.

\subsection{Engine}

Para tornar o código mais estruturado e melhorar o desempenho do mesmo, o jogo conta com uma engine (HERWIG e PAAR, 2002). Ela oferece ao programador um framework que agiliza o desenvolvimento, pois controla as funções básicas essenciais para qualquer jogo (LEWIS e JACOBSON, 2002). 
A engine utilizada no "Daphnia World" foi desenvolvida em paralelo com a primeira versão do jogo. Essa engine é responsável por controlar os elementos exibidos na tela. Para isso é utilizada uma estrutura baseada em camadas transparentes que são sobrepostas. Cada camada possui um elemento visual do jogo. Outra funcionalidades é a linha de tempo, formada por quadros. Esse recurso permite controlar a ocorrência de eventos no jogo (BISPO, ZABEU, et al., 2010).

\section{A Nova Versão do Jogo}

Quando o jogo inicia, é apresentado a tutora do jogo, uma tecnologia de saneamento ambiental, essa personagem é responsável por apresentar toda interface do jogo, bem como dar explicações das fontes poluidoras presentes no decorrer da fase e dos itens presentes na loja. Após sua apresentação e explicação da interface o jogador assume o controle da Daphnia. A interação do usuário com a Daphnia ocorre pelas setas do teclado.

A partir desse ponto o objetivo do jogador é levar a Daphnia a um local seguro para se reproduzir. A Daphnia encontra nesse percurso diversas ameaças naturais, como predadores, e diferentes tipos de poluição. Para vencer esses desafios o jogador pode contar com itens como chuva, para diluir a poluição, e proteção, que torna a Daphnia intocável por um período de tempo. Esses itens estão acessíveis por atalhos e ícones na interface do jogo.

Completando o objetivo é apresentado ao jogador uma cena rápida da Daphnia reproduzindo-se. Caso contrário uma tela de objetivo não completado é apresentada. Nos dois casos uma opção de reiniciar o jogo é oferecido ao jogador.

Essa dinâmica foi mantida na nova versão do jogo, em relação a versão anterior apresenta-se as seguintes mudanças:

- Melhorias na interface;

- Novos objetos e desafios;

- Novas funcionalidades na engine.

Os resultados acima estão apresentados em maior detalhe nas próximas subseções.

\subsection{Melhorias na interface}

Assim que o jogo inicia, é apresentada a tecnóloga, personagem responsável por instruir o jogador no decorrer das fases. Na nova versão do jogo, a tecnóloga possui uma apresentação remodelada, dando mais destaque para personagem e suas falas. A Figura 1 ilustra a antiga e a nova versão da apresentação da tecnóloga. 

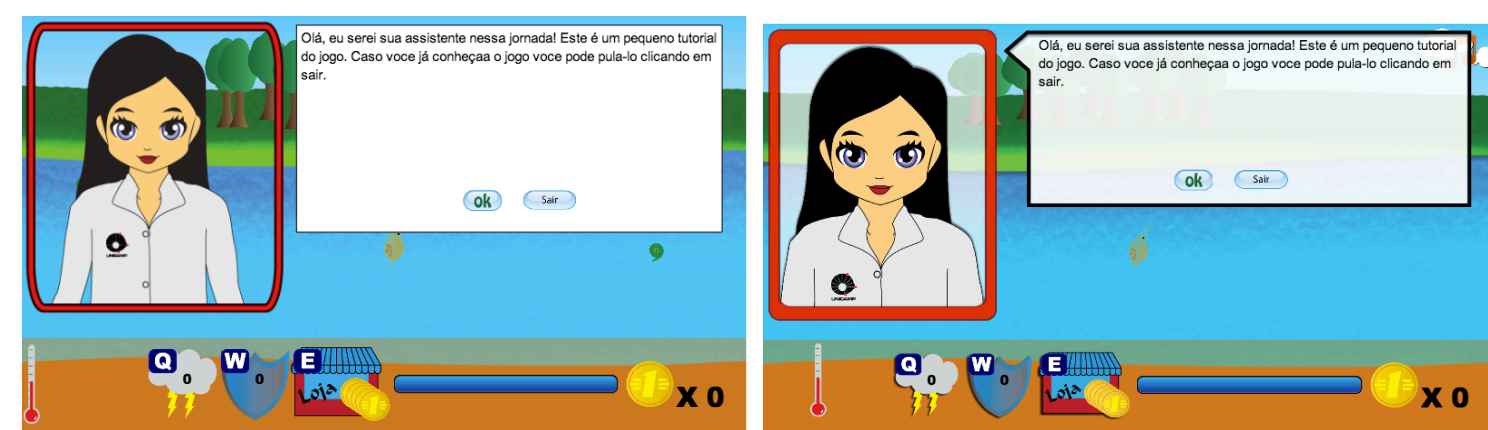

Figura 1 Apresentação da tecnóloga na versão anterior do jogo. Nova apresentação da tecnóloga.

Para conseguir vencer os desafios proposto pelo jogo, o jogador pode adquirir itens através da loja. Para facilitar esse tipo de atividade a interface da loja foi repensada. Agora, ao comprar um item, o jogador recebe uma indicação clara da ação executada. A Figura 2 mostra a versão anterior da loja e a nova versão da loja.
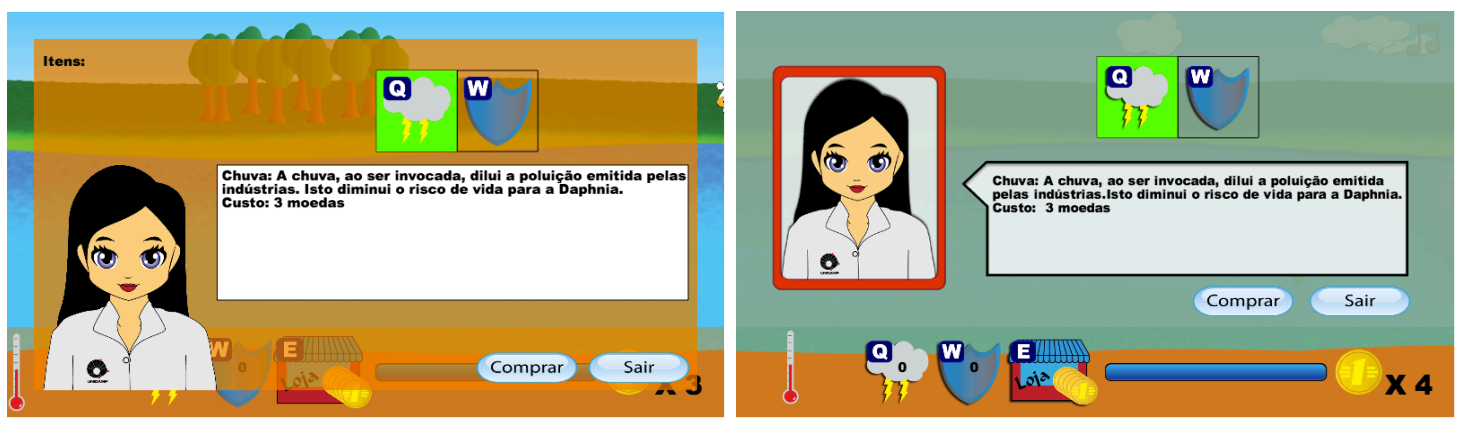

Figura 2 Interface da versão anterior da loja, à esquerda. Nova interface da loja, à direita.

A indicação de aumento de temperatura foi outro ponto alterado na interface. Quando esse evento acontecia, o termômetro mostrava o aumento, mas de forma muito sutil, chegando a não ser percebida pelo jogador. A Figura 3 mostra a versão anterior do termômetro do jogo e ilustra a mudança.
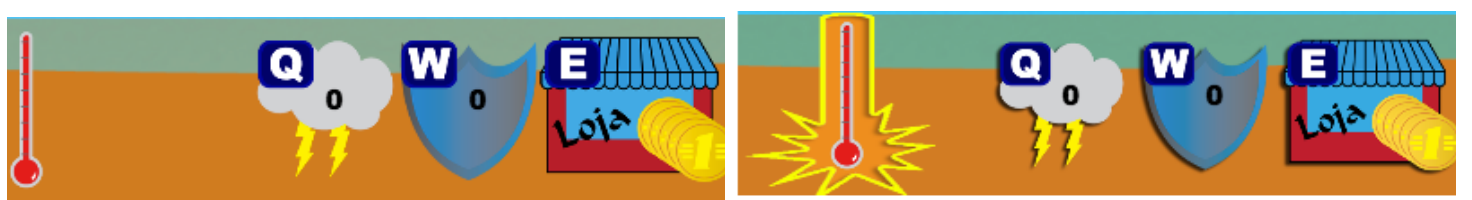

Figura 3 Versão anterior da indicação de aumento de temperatura. Nova indicação de aumento de temperatura.

A nova versão do jogo também conta com uma forma nova de exibir a poluição. Na versão anterior, a emissão de poluentes era representada por um semicírculo que crescia conforme passava o tempo. Essa representação não era adequada, porque não representava como a poluição se dilui em um curso de água. Na nova versão, a poluição é representada por uma mancha que cresce conforme o fluxo do rio e que se espalha e enfraquece conforme a 
distância do emissor, o que é muito mais próximo do que acontece realmente. A ilustração das fábricas também foi alterada, com a inclusão de um cano de descarga para indicar a saída dos poluentes. A Figura 4 ilustra tanto a versão anterior das fábricas e da poluição quanto a nova versão dos mesmos objetos.
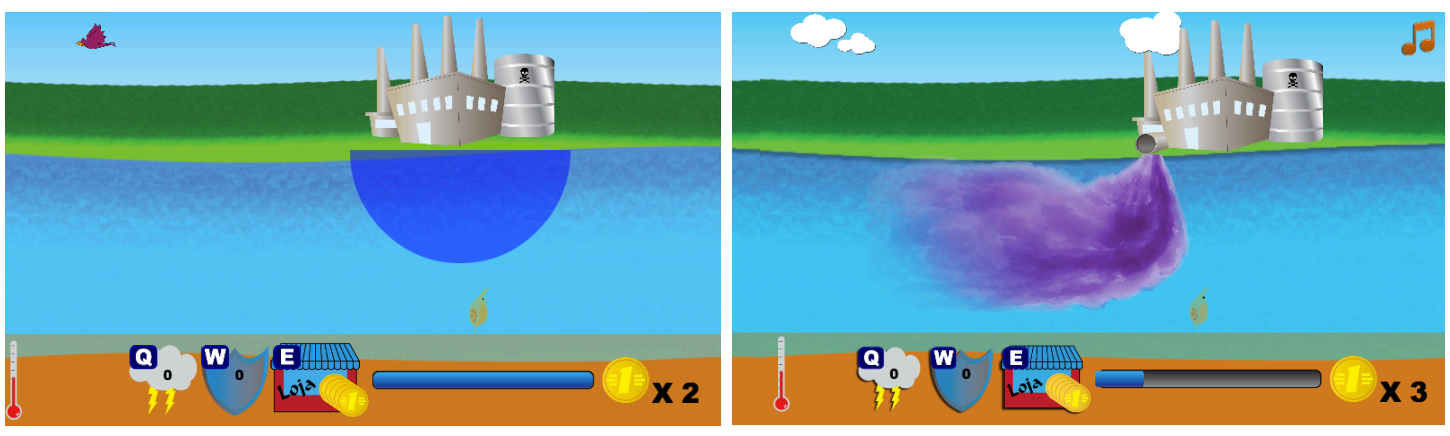

Figura 4 Poluição das Indústrias da versão anterior. Nova forma de representar a poluição no jogo.

Por fim, ao final do jogo, foi alterado o vídeo que era exibido ao completar o objetivo. Foi criada uma animação, utilizando a engine do jogo, com a personagem Daphnia, simulando o nascimento de seu filhotes.

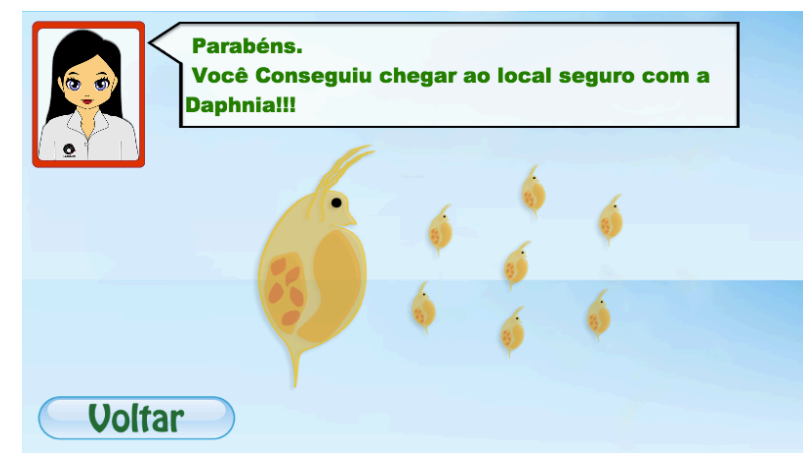

Figura 5 Nova tela de objetivo concluído.

\subsection{Novos objetos e desafios}

Visando tornar o jogo mais dinâmico e oferecer novos desafios, novos objetos foram adicionados: nuvens no céu, folhas nos rios, entre outros. A Daphnia é carregada pela correnteza quando o jogador não a movimenta. $\mathrm{O}$ objetivo das folhas é indicar a direção da correnteza. Com as nuvens o plano de fundo do jogo passa a ser menos estático que nas versões anteriores, visto que esse objeto também se locomove no ambiente. Vale ressaltar que vários desse objetos aparecem em diversos momentos no decorrer do jogo. 


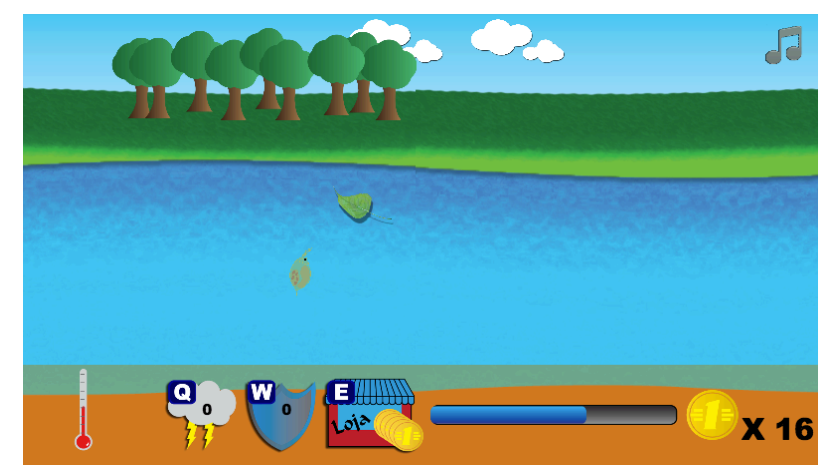

Figura 6 Folha no rio e nuvens: novos objetos inseridos no jogo.

Para tornar o jogo mais motivador, foram incluídos novos obstáculos, como novas fontes de poluição que exploram outros conceitos sobre ecotoxicologia. Temos, como exemplo, a fazenda de criação de gado como mostra a Figura 7. A fazenda, a princípio, não emite nenhuma poluição. Mas quando chove próximo à localização de uma criação de gado, os resíduos oriundos dessa criação são carregados para o rio, tornando-se poluição.

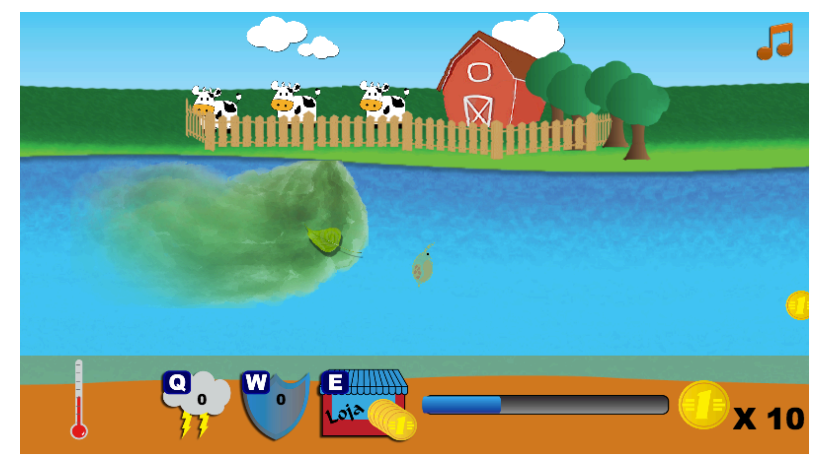

Figura 7 Poluição emitida pela fazenda ao chover na região.

Outro elemento adicionado que interage com o jogador são casas que possuem latas de lixo. Essas latas também tem seus resíduos carregados para o rio após uma chuva. Ao fundo das casas foi incluída uma representação de uma área urbana. A Figura 8 ilustra as casa e latas de lixo após usar o item de chuva.

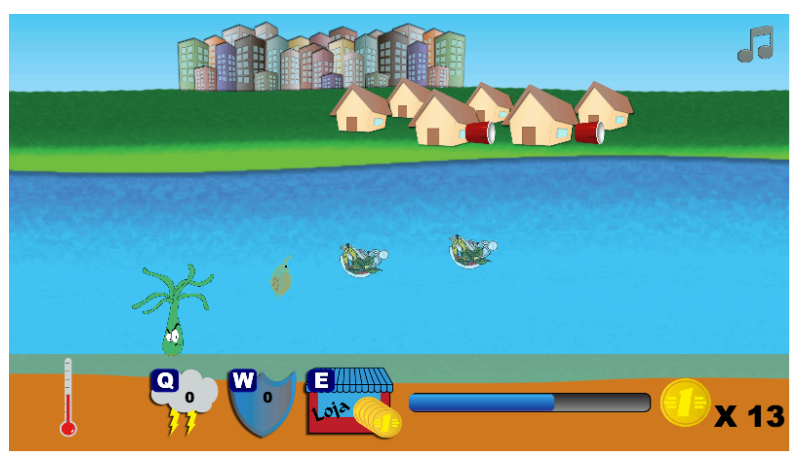

Figura 8 Lixo da cidadã carregado pela chuva é levado para o rio. 
Por fim, próximo de uma área urbana, foi incluído um lixão. Esse objeto se comporta de forma semelhante às indústrias, sendo um emissor de poluição constante (chorume). Quando ocorre um evento de chuva, a emissão é diluída no rio.

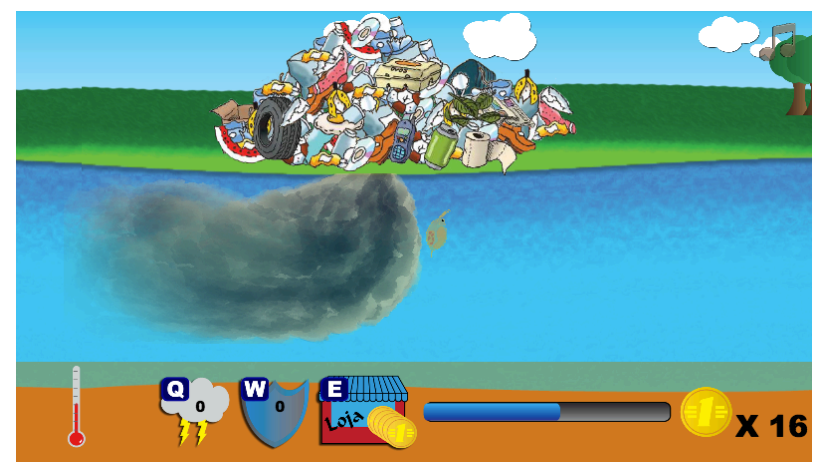

Figura 9 Lixão presente próximo a cidade.

\subsection{Novas funcionalidades na engine.}

Várias mudanças foram feitas na engine do jogo, visando oferecer um melhor desempenho e incluir novas funcionalidades. O principal recurso incluído na nova versão da engine é a possibilidade de manipular arquivos de áudio. Efeitos sonoros podem melhorar a percepção de vários elementos, como animais, eventos como a chuva e despejo de resíduos pelas indústrias. O uso de som também torna o jogo mais interessante.

A engine agora provê funções que permite maior manipulação por parte do programador:

- Definir arquivo de áudio;

- Definir duração do áudio;

- Definir volume do áudio;

- Tocar e parar áudio.

Além dessa nova funcionalidade, algumas otimizações foram feitas. Por exemplo, ao longo do código muitas funções que eram repetidas. Para evitar esse tipo de repetição, foi aplicado melhor o conceito de programação orientada a objetos, principalmente o conceito de herança de classes.

\section{Conclusão}

O Daphnia World apresenta, em sua nova versão, várias alterações de interface que visam melhorar a iteração do usuário com o jogo. Foram incluídos novos elementos, como fontes de poluição de origem urbana e de pecuária, tornando o jogo mais desafiador, além de aumentar os conceitos trabalhados sobre Ecotoxicologia.

Além disso, a engine do jogo foi otimizada e atualizada para que possa manipular, além de imagem, áudio: com isso o jogo tornou-se mais interessante. Os efeitos sonoros enriqueceram a percepção de vários elementos. Com esses resultados, a nova versão do jogo Daphnia World se torna mais dinâmica e interessante ao jogador. 
O HTML 5 é suportado pela maioria do navegadores, mesmo que ainda não esteja em sua versão final. Até sua versão final estar disponível, é esperado que todos os navegadores tenham suporte a tal tecnologia.

\section{Referências}

BISPO, D. M. et al. JOGO COMPUTACIONAL PARA INTRODUÇÃO A ECOTOXICOLOGIA. XXI simpósio Brasileiro de informática na Educação, João Pessoa, 2010.

GIMP. GIMP. GIMP. Disponivel em: <http://www.gimp.org>. Acesso em: 8 jul. 2013.

HAZAËL-MASSIEUX, D. JAVASCRIPT WEB APIS. w3.org, 2013.

Disponivel em: <http://www.w3.org/standards/webdesign/script.html>. Acesso em: 8 Julho 2013.

HERWIG, A.; PAAR, P. Game Engines: Tools for Landscape Visualization and. In: VERLAG, W. Trends in GIS and Virtualization in Environmental Planning and Design. heidelberg: Anhalt University of Applied Sciences, 2002. p. 161-172.

IBGE. PNAD: De 2005 para 2011, número de internautas cresce 143,8\% e o de pessoas com celular, 107,2\%. IBGE, 16 maio 2013. Disponivel em: $<$ http://saladeimprensa.ibge.gov.br/noticias?view=noticia\&id=1\&idnoticia=2382 \&busca=1\&t=pnad-2005-2011-numero-internautas-cresce-143-8-pessoascelular-107-2>. Acesso em: 8 jul. 2013.

LEWIS, M.; JACOBSON, J. Game Engines in Scientific Research. COMMUNICATIONS OF THE ACM, 45, n. 1, 2002.

MORAIS, S. N.; BORGES, M. A. F. Jogo educativo sobre Ecotoxicologia em HTML5, 2012.

MOZZILA. Canvas. Mozilla Developer Network, 1 jul. 2013. Disponivel em: <https://developer.mozilla.org/en/docs/HTML/Canvas>. Acesso em: 20 jul. 2013.

TRUHAUT, R. Ecotoxicology: Objectives, Principles and Perspectives. In: Ecotoxicology and Environmental Safety. New York: [s.n.], v. 1, 1977. p. 151-173.

W3C. HTML Canvas 2D Context. W3, 5 Julho 2013. Disponivel em: <http://www.w3.org/html/wg/drafts/2dcontext/html5_canvas/>. Acesso em: 8 Julho 2013.

W3C. HTML5 Introduction. W3Schools. Disponivel em: <http://www.w3schools.com/html/html5_intro.asp>. Acesso em: 8 jul. 2013. 